Campaign for Mentally Handicapped People $(\mathrm{CMH})$ and what comes across loud and clear is that $\mathrm{CMH}$ is opposed to these decisions remaining in the hands of doctors and parents and would like to see similar legislation introduced here. This opposition is based not only on two British cases used as 'starting points', those of Baby Alexandra and the late Dr Leonard Arthur but on the assumption that decisions to allow severely disabled babies to die somehow devalue all handicapped people and threaten their security. I believe that this assumption is wrong and does scant justice to the many paediatricians and others who are at the forefront of promoting and improving services for the handicapped. At the same time surely it is not inconsistent for them to express concern at the growing tendency to preserve life, just because it is possible technically and without regard to the consequences. Although I disagree with the position adopted by $\mathrm{CMH}$ I think that this is an accurate and useful summary of the current turmoil. Like Professor Ian Kennedy, who writes the foreword, $\mathrm{CMH}$ would like to see the acceptance of a number of principles on which decisions could be based and those recently published jointly by a number of American organisations are quoted. Most of these already dictate clinical practice in this country but some, while sounding noble and incontrovertible, are difficult to put into effect when faced with individual infants suffering from the injustices of biology and when aware of the realities of the medical, family and other resources available. They also leave much to individual interpretation and unless we adopt the American solution of creating Infant Care Review Committees (ICRCs) we must continue to trust doctors and parents to do the best they can. ICRCs sound fine in theory and as originators of guidelines and objective reviewers of policy and practice they can have an important role in major hospitals. How well they can respond, often at short notice, to the unique problems posed by an individual infant in an individual family, remains to be seen.

Professor Kennedy believes that it is really the doctor who makes the decision and the parents just go along with it. Apparently he does not necessarily disapprove of this as long as others get involved and the decisions are based on clearly articulated and agreedupon ethical principles. Most of us would agree with this provided that the parents' views are heard and given appropriate weight. Agencies of the
State, such as the courts, should be used only as a last resort.

PROFESSOR A G M CAMPBELL Department of Child Health, University of Aberdeen

\section{The Politics of Schizophrenia: Psychiatric Oppression in the United States}

David Hill, 577, xii pages, Lanham, Maryland, $£ 32.80$, University Press of America, 1984

This is not an attractive book, 589 pages of unappealing typescript, 'originally written as a dissertation for a Doctorate degree in Clinical Psychology. Rather than trying to write one version to meet the elitist requirements of an academic institution and a second, more readable, version, I tried to walk a tightrope between the two, often erring on the side of unnecessarily long words and sentences'. The University of Cincinnati was apparently satisfied.

A History of Madness, a sketchy, random, reworking of that territory made familiar by Szasz, is followed by nearly 100 pages devoted to Kraepelin and Bleuler, and how they provide the rationale for mass murder. Dr Hill, however, fundamentally misunderstands the history of medicine. He seems unaware that the identification of a syndrome (a set of concurrent symptoms) has often preceded knowledge of aetiology. Dr Hill actually cites Parkinson's identification of the shaking palsy as a praiseworthy example of the medical method shortly before writing, 'To proclaim a disease entity in the absence of a proven aetiology locates Kraepelin on the borders, at best, of medical science'. Lost amongst all this is an important point concerning the folly of attempting to understand people without considering the effect of one upon another. Laing demolished Kraepelin in this respect, however, twenty five years ago, and in one page.

Dr Hill advises the reader to 'skip' Part Four of his book, The Scientific Status of 'Schizophrenia', and, 'to take my word for it', that it has none. Despite his repeated attacks upon the scientific competence of his colleagues, Dr Hill assiduously protcts his readers from exposure to any data, even in the section on epidemiology. Perhaps he fears they will be innumerate as well as illiterate. All pretence at objectivity is abandoned in the section on treatment. The history of leucotomy, however, is terrible enough without weasel implications that it is a current treatment for schizophrenia. Even this section of the book is not well done; Frank (1) presented a much more comprehensive version of the 'Californian' case against electroconvulsive therapy (ECT) and leavened the anger, not with self righteousness, but with wit. Finally the purpose of the book is revealed: Dr Hill and his colleagues have developed another bloody psychological test.

I did not enjoy this book. Being simultaneously harangued and patronised by someone who does not really seem to understand is particularly irritating, (perhaps being a psychiatric patient feels like that). However, it could be argued that I cannot free myself from identification with the outgroup 'psychiatrists', and that I am offended by being betrayed as a fool who tortures those whom the evil forces of capitalism have sent his way. Nevertheless, at least three groups should be able to use a well written radical critique of psychiatry. The Politics of Schizophrenia could have been a scholarly book, including discussions of the issues, backed by an extensive presentation of the relevant literature. Despite being a doctoral thesis, this book wholly fails to meet that goal, the bibliography has many glaring omissions, and there is no index. Dr Hill even introduces a new scientific convention, quoting authors without giving the reference. Books can also be a medium for the transmission of new ideas, new ways of looking at the world. The author seems unaware, or at least unwilling to acknowledge, that most of his ideas have been around for a generation, not necessarily accepted, of course, but even the better psychiatric textbooks now include them. Lastly, this could have been a work of polemic, but here is its saddest failure. I still remember the excitement I felt when I first read The Divided Self. I did not agree with everything Laing wrote, but it opened my eyes. I cannot believe that anyone will react, alas, in that way to this book. It is too long, too expensive, too repetitive and too shrill. If Dr Hill wants to write a book that will make people change their minds, then he has still to write it.

\section{References}

(1) L R Frank, ed. The history of shock treatment. San Francisco: Leonard Roy Frank, 1978.

G P PULLEN Littlemore Hospital, Oxford 